Research Paper:

\title{
Prevalence of Catatonic Schizophrenia Symptoms in a Psychiatric Hospital: A Retrospective Study
}

\author{
Javad Setare $^{1}$ (D), Aram Karimian² (D), Maryam Shoja ${ }^{3}$ (D), Fereshteh Bakhshian ${ }^{4}$ (D), Seyed Reza Saadatmehr ${ }^{5 *}$ (D)
}

1. Psychiatry and Behavioral Sciences Research Center, Mazandaran University of Medical Sciences, Sari, Iran.

2. Department of Emergency Medical Sciences, School of Paramedical Sciences, Kurdistan University of Medical Sciences, Sanandaj, Iran.

3. Department of Nursing, School of Nursing and Midwifery, Babol University of Medical Sciences, Babol, Iran.

4. Department of Psychology, Faculty of Social Science, Razi University, Kermanshah, Iran.

5. Department of Nursing, University of Social Welfare and Rehabilitation Sciences, Tehran, Iran.

\begin{tabular}{|l|l|}
\hline $\begin{array}{c}\text { Use your device to scan } \\
\text { and read the article online }\end{array}$ & $\begin{array}{l}\text { dtation Setare, J., et al., 2018. Prevalence of Catatonic Schizophrenia Symptoms in a Psychiatric Hospital: A Retrospective } \\
\text { Study. Journal of Client-Centered Nursing Care, 4(3), pp. 139-144. https://doi.org/10.32598/jccnc.4.3.139 }\end{array}$ \\
\hline
\end{tabular}

\section{(c) (1) (8)}

Article info:

Received: 23 Jan 2018

First Revision: 10 Feb 2018

Accepted: 28 May 2018

Published: 01 Aug 2018

Keywords:

Catatonia, Schizophrenia, Prevalence, Mental disorder

\section{A B S T RA C T}

Background: Catatonia occurs as a complication of various medical and psychological illnesses that can be treated when diagnosed. Despite the high incidence of catatonia, the problem is poorly recognized. This study aimed at investigating the prevalence of catatonia and related factors in its diagnosis within a five year period in hospitalized patients of Zareh Psychiatric Center, Sari, Iran using computerized archive of records.

Methods: It was a descriptive and retrospective study. The records of all patients with mental disorders admitted to Zareh Hospital between 2010 and 2014 were assessed. The data were collected using a demographic questionnaire and the Northoff Catatonia Scale (NCS). Then analyzed by statistical tests of multivariate logistic regression in SPSS-PC V. 20

Results: Only $0.26 \%$ (26 per 10000 population) of patients had experienced catatonic schizophrenia during a five year period, including 42.11 men and 57.89 women. The prevalence of catatonic schizophrenia was significantly correlated with gender and age $(\mathrm{P}<0.05)$. Of the patients, $68.42 \%$ had a history of medication therapy and or hospitalization and $21.5 \%$ had a history of physical disorders. There was no significant relationship between the mean score of movement, emotional and behavioral changes with sex, education and age groups $(\mathrm{P}<0.05)$.

Conclusion: Because many catatonic patients had a combination of medical and psychiatric problems, psychiatrists and psychiatric nurses are suggested to assess catatonia symptoms in both internal and psychiatric wards.

\section{* Corresponding Author:}

Reza Saadatmehr, MSc.

Address: Department of Nursing, University of Social Welfare and Rehabilitation Sciences, Tehran, Iran.

Tel: +98 (912) 1464553

E-mail:rsaadatmehr@yahoo.com 


\section{Highlights}

- The prevalence of catatonic symptoms in men was lower than that in women.

- The prevalence of catatonic schizophrenia symptoms is higher at younger ages.

- Reducing the duration of admission can greatly help in lowering the cost of treatment of catatonia symptoms.

\section{Plain Language Summary}

Catatonia is a complex neuropsychological disorder which refers to a number of abnormalities in movement, volition, speech, and behavior. Historically, the term catatonia has been associated with schizophrenia and psychoses, but it can occur with a wide range of conditions. Catatonia is potentially life threatening. The results obtained in the present study have shown that only $0.26 \%$ of mental disorder patients who were hospitalized during past five years, were catatonic schizophrenia, also gender and age are associated with the prevalence of catatonic schizophrenia.

\section{Background}



atatonia is a neurological syndrome that can occur due to physical or mental disorders (Daniels 2009). About 10\% of catatonic patients are admitted to mental health departments (Bartolomi et al. 2012). Studies of adult patients with schizophrenia and mood disorders in Finland reveals that incidence of catatonic cases varies between $10 \%$ and 38\% (Waris et al. 2014). The incidence of catatonia among acute psychiatric episodes is between $6 \%$ and $38 \%$, and only 7 to $17 \%$ of those are catatonic schizophrenia. Some studies have shown that 1 catatonia case is found in 1000 of general population and it accounts for more than $5 \%$ of all schizophrenia cases (Tandon 2013; Fink \& Taylor 2009). In total, schizophrenic catatonia accounts for 0.2 to $3 \%$ of all types of schizophrenia (Tandon 2013).

According to DSM-IV, the following symptoms can be seen in catatonic patients: decreased bodily movements in the form of catalepsy (hypokinesia), excessive motor activity hyperkinesia, extreme negativism or mutism, movements such as a particular mode or posturing and stereotyped movements (echopraxia) and unsolicited repetition of vocalizations made by another person in its profound form (echolalia) (Tandon 2013; Kavak 2018). Catatonia is also classified in the DSMIV and DSM-V under catatonic disorders due to general and emergency medical conditions, schizophrenia catatonia, and certain types of mood disorders. DSM-IV defines catatonia as a subset of schizophrenia or mood disorders with at least two of the five symptoms while these conditions are not necessary for medical catatonia (Tandon 2013; Waris et al. 2014).

Although catatonic disorders are not specific to any disease, they are seen most commonly in psychotic disorders, bipolar disorders, depression, conversion disorders, dementia, and other organic disorders such as epilepsy, metabolic disorders, and use of some drugs such as neuroleptic drugs. A variety of catatonic symptoms have been reported among schizophrenic patients and those with mood disorders. Although catatonia is historically more related to schizophrenia, its prevalence is much higher in mood disorders. For example, in a sample of 55 patients with catatonia, only 4 were schizophrenic and two-third of them were patients with emotional disorders, especially mania (Tandon 2013; England et al. 2011). Similarly in another catatonia study, only one person had schizophrenia and 9 patients had affective disorders (Usman 2011).

Despite the high incidence of catatonia, this disorder has not been recognized correctly; therefore it cannot be treated when diagnosed. However, early detection and rapid treatment of catatonia are important to prevent its clinical complications and reduce medical costs (Martényi et al. 2001). Nurses are the main members of therapeutic team and play an essential role in identifying these symptoms. Because no study has been conducted about the incidence of catatonia symptoms in Iran, conducting such a research was necessary.

In this study, we examined the prevalence of catatonia within five years and assessed its related diagnoses in hospitalized patients in Zareh Psychiatric Center, sari, Iran using computerized registration records archive. 


\section{Materials and Methods}

Our research was a descriptive, retrospective study using available data. All the medical records of catatonic patients who were admitted to Zareh Psychiatric Hospital between 2010 and 2014 and were hospitalized for more than 24 hours, with at least two symptoms of catatonia based on DSM-IV criteria (hypokinesia, hyperkinesia, mutism, echolalia, echopraxia) were included. The study data were collected using a demographic questionnaire and the Northoff Catatonia Scale (NCS). The demographic questionnaire included 7 questions on age, sex, marital status, and education and some information about the catatonia mutism, negativism, rigidity, excitement and comorbidity, and also addiction (Leslie \& Rosenheck 2004).

NCS consists of 3 subscales (movement, emotional and behavioral) and 40 items; 13 items on movement symptoms (mannerism, stereotypy, etc.), 12 on emotional symptoms (impulsivity, aggression, etc.) and 15 on behavioral symptoms (grimacing, echolalia, etc.). Each statement is answered by a 3-point Likert-type scale $(0=$ no disorder, $1=$ moderate disorder with probability of interruption, $2=$ permanent and severe disorder without any interruption). The total NCS score $>7$ cuts off catatonic patients from non-catatonics with the sensitivity and specificity of $100 \%$. The three subscales in NCS (motor, emotional, and behavioral) have shown a positive and significant correlation with total NCS score $(\mathrm{P}<0.0001 ; \mathrm{r}=0.85-0.94)$. Diagnosis of catatonic syndrome is made by at least one sign from each group (motion, emotional, behavioral) independent of the underlying disease (Northoff 1999).

In this study, the instruments were first translated into Persian and along with the original instrument, were provided to five psychiatric professors of Zareh Hospital in Sari, and their proposed revisions were applied in translation. The tool was then translated back into English and then into Persian. Next, the tool was reassessed by the professors. Based on the Lawshe method, the Content Validity Range (CVR) was 0.99, and the Content Validity Index (CVI) was 0.85, which indicated high validity of the tool. According to search conducted in databases, this tool has not been used in any study in Iran. To verify reliability, internal consistency was calculated (Cronbach alpha $=0.87$ ), which indicates its high reliability. Multivariate logistic regression was conducted and the data were statistically analyzed using descriptive and inferential tests in SPSS V. 20.

\section{Results}

During the study period (2010-2014) the number of clients of Zareh Psychiatric Center were 7197 (Table 1) patients, of whom 19 were identified with catatonia syndrome. The incidence of catatonia syndrome in these years was $0.26 \%$ (26 per 10000 population), including $0.15 \%$ men and $0.55 \%$ women. According to Table 2, there was no significant difference in the mean score of movement, emotional and behavioral changes at the significance level of 0.05 with regard to sex, education and age groups $(\mathrm{P}>0.05)$.

Regarding the medical conditions of the patients with catatonia, $68.42 \%$ had history of hospitalization for various reasons and $21.5 \%$ had physical illness records (Table 3). The maximum severity of changes reported for negativity and mutism were $73.7 \%$, and $89.5 \%$ of the patients in emotional aspects experienced ambivalence, and in motor aspect, $78.9 \%$ of patients had inflexibility changes. Generally, there was no significant difference in the mean score of motor-emotional-behavioral changes at the significance level of 0.05 regarding sex, education, and age groups $(\mathrm{P}<0.05)$ (Table 4$)$.

\section{Discussion}

The incidence of catatonia syndrome during 2010 to 2014 was $0.26 \%$ (26 per 10000 patients), including $27.59 \%$ females and $72.41 \%$ males (42.11 men and

Table 1. Prevalence and distribution of patients with catatonia symptoms $(n=19)$

\begin{tabular}{lcccccc}
\hline \multirow{2}{*}{ Variable } & & \multicolumn{2}{c}{ The Patients Admitted } & \multicolumn{2}{c}{ Prevalence } & \multirow{2}{*}{$\begin{array}{c}\text { The Percentage } \\
\text { of Patients }\end{array}$} \\
\cline { 3 - 6 } & & No. & $\%$ & No. & $\%$ & 42.11 \\
\hline \multirow{3}{*}{ Gender } & Male & 5211 & 72.41 & 8 & 0.15 & 57.89 \\
& Female & 1986 & 27.59 & 11 & 0.55 & 0.26 \\
\hline
\end{tabular}


Table 2. Multivariate logistic regression results to examine the relationship between demographic indicators and the prevalence of catatonia $(n=19)$

\begin{tabular}{cccccccccc}
\hline $\begin{array}{c}\text { Independent } \\
\text { Variable }\end{array}$ & $\begin{array}{c}\text { Parameter } \\
\text { Estimation }\end{array}$ & $\begin{array}{c}\text { Standard } \\
\text { Error }\end{array}$ & Wald & $\begin{array}{c}\text { Degrees of } \\
\text { Freedom }\end{array}$ & Sig. & $\begin{array}{c}\text { Odds } \\
\text { Ratio }\end{array}$ & $\begin{array}{c}\text { The Odds Ratio Confi- } \\
\text { dence Interval 95\% }\end{array}$ \\
\hline Gender & -1.535 & 0.471 & 10.629 & 1 & 0.001 & 0.215 & 0.086 & 0.542 \\
Lower Limit & $\begin{array}{c}\text { Upper } \\
\text { Limit }\end{array}$ \\
\hline Age & -0.050 & 0.017 & 8.511 & 1 & 0.004 & 0.952 & 0.920 & 0.984 \\
Education & -0.541 & 0.466 & 1.341 & 1 & 0.246 & 0.582 & 0.234 & 1.452 \\
\hline Fixed value & -2.731 & 0.744 & 13.470 & 1 & 0.000 & 0.065 & & \\
\hline
\end{tabular}

Client- Centered Nursing Care

Table 3. Frequency indexes of medical condition of the patients with catatonia $(n=19)$

\begin{tabular}{cccccc}
\hline \multicolumn{2}{c}{ Drug History } & & \multicolumn{2}{c}{ Physical History } & \multicolumn{2}{c}{ History of Hospitalization } \\
\hline No. & $\%$ & No. & $\%$ & No. & $\%$ \\
\hline 13 & 68.42 & 4 & 21.05 & 13 & 68.42 \\
\hline
\end{tabular}

Client- Centered Nursing CareX

57.89 women). The prevalence of catatonic symptoms in men was lower than that of women. Moreover, it was found to be more common at earlier ages. In examining the medical records of the patients, $42.68 \%$ had medication history and or history of hospitalization and $21.5 \%$ of the cases had records of physical problems.

Bouza, Lápez-Cuadrado and Amate (2010) in a total of 16776 patients (average age 43 years, 65\% male) found that $61 \%$ of cases had at least one physical illness and $32 \%$ had more than one physical illness. According to the Charlson comorbidity index, $20 \%$ of cases of a phys- ical illness have severe prognosis. In investigating the prevalence of catatonic schizophrenia symptoms, it was found that physical illness had been appeared early in life (50\% of cases were $15-31$ years) which progressed rapidly with age; therefore, $84 \%$ of older people than 53 years had at least one physical illness.

In a study entitled "Catatonic features in adolescents with schizophrenia with and without a comorbid pervasive developmental disorder", all adolescents with schizophrenia showed some lifetime catatonic features. Approximately $78 \%$ had already expressed these fea-

Table 4. The severity of motor-behavioral-emotional changes $(n=19)$

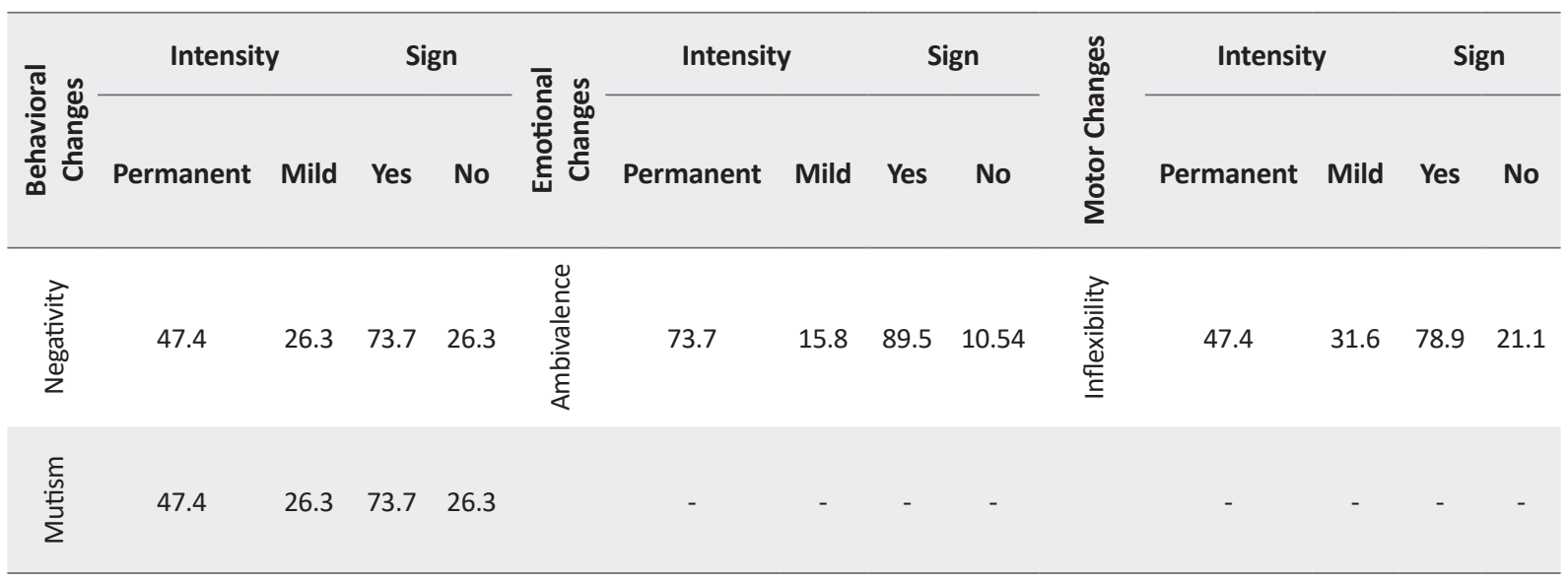

Client- Centered Nursing CareX 
tures before the age of 10 (Waris et al. 2014). Another study with the aim of determining the clinical course and epidemic prevalence of catatonic schizophrenia found the same results. According to the results of this study, the prevalence of catatonic schizophrenia was higher in women than in men in the general population $(\mathrm{P}<0.01)$ (Guggenheim \& Babigian 1974)

Based on 798 cases from a county-wide psychiatric register. The cases in this catatonic cohort represent 10 per cent of all patients ever to receive a diagnosis of schizophrenia in the Monroe County Psychiatric Case Register. The 7-year prevalence of catatonic schizophrenia, based on the span of this study, is close to 1 per 1,000 county inhabitants. Far from being a vanishing entity, the catatonic type of schizophrenia now represents 5 per cent of all first diagnoses of schizophrenia. There are significantly more women than men in the catatonic cohort when compared to the register schizophrenics, the entire register population, or the Monroe County population $(\mathrm{P}<0.02)$. However, these findings were not congruent with our study. This difference can be attributed to factors such as the level of awareness of this disorder, availability and diversity of referral centers and community information of psychiatric disorders and psychiatric services and how to access these centers.

Similar to current study, some other studies found that age, sex, and history of physical illness have an effect on the incidence of schizophrenia (Quigley, Lommel \& Coffey 2009; Guggenheim \& Babigian 1974); based on 798 cases from a county-wide psychiatric register. The cases in this catatonic cohort represent 10 per cent of all patients ever to receive a diagnosis of schizophrenia in the Monroe County Psychiatric Case Register. The 7-year prevalence of catatonic schizophrenia, based on the span of this study, is close to 1 per 1,000 county inhabitants. Far from being a vanishing entity, the catatonic type of schizophrenia now represents 5 per cent of all first diagnoses of schizophrenia.

There are significantly more women than men in the catatonic cohort when compared to the register schizophrenics, the entire register population, or the Monroe County population $(\mathrm{P}<0.02)$ Given the experience of a combination of medical and psychiatric problems by most catatonic patients, it is recommended that psychiatrists and psychiatric nurses assess catatonia symptoms in either medical or psychiatric wards (Daniels 2009).

Because of poor conditions of health care organizations and the need for long-term care of these patients, they experience many physical and psychological prob- lems (Ungvari 2018). Considering that adverse effects of physical and psychological problems can lower the quality of life in patients with schizophrenic catatonic disorders, with decreasing and controlling these symptoms their quality of life may somewhat improve. Therefore, it is important to pay attention to the symptoms of patients and their timely treatment.

Because nurses are at the first line of treatment and the main member of health care team, they play a key role in diagnosis and treatment of patients with catatonia. Considering the very low rate of schizophrenic catatonia among patients admitted to psychiatric centers, the researchers suggest a prospective study with the aim of identifying catatonic symptoms to prevent its physical and psychological complications. In addition, by reducing the length of admission, it can greatly reduce the cost of treatment.

\section{Ethical Considerations}

\section{Compliance with ethical guidelines}

The project was approved by the Behavioral Sciences Research Center of Mazandaran University of Medical Sciences. The coordination was carried out with the Administrator of the Hospital and the Head of the Medical Records, Department of Zareh Hospital in Sari to obtain permission and access to the medical files. The investigations were performed by the principle researcher and ethical standards and also the confidentiality of patients' information were considered.

\section{Funding}

This article is the result of a research proposal approved by the Center for Research in Behavioral Sciences of Mazandaran University of Medical Sciences with the code of 1388 and funded by Research Deputy of Mazandaran University of Medical Sciences during 2015-2016.

\section{Authors contributions}

Conceptualization: Javad Setareh and Seyed Reza Saadatmehr; Methodology: Javad Setareh, Fereshteh Vakhshian, Aram Karimian; Investigation: Seyed Reza Saadatmehr and Aram Karimian; Writing-original draft: Sayed Reza Saadatmehr and Maryam Shoja; Writing-review \& editing: Sayed Reza Saadatmehr, Aram Karimian, Fereshteh Bakhshian; and Supervision: Javad Setareh. 


\section{Conflicts of interest}

The authors declared no conflict of interest.

\section{Acknowledgements}

The authors express their gratitude to the chairman, director and all medical staff of Zareh Hospital and Dr. Kian Norouzi, who assisted us in this project.
Tandon, R., et al., 2013. Catatonia in DSM-5. Schizophrenia Research, 150(1), pp. 26-30. [DOI:10.1016/j.schres.2013.04.034]

Ungvari, G. S. et al., 2018. Schizophrenia with prominent catatonic features: A selective review. Schizophrenia Research, 200, pp. 77-84. [DOI:10.1016/j.schres.2017.08.008]

Usman, D. M. et al., 2011. Comparison of catatonia presentation in patients with schizophrenia and mood disorders in Lagos, Nigeria. Iranian Journal of Psychiatry, 6(1), pp. 7-11. [PMCID]

Waris, P. et al., 2014. Catatonic features in adolescents with schizophrenia with and without a comorbid pervasive developmental disorder. Child and Adolescent Psychiatry and Mental Health, 8(1), pp. 1-7. [DOI:10.1186/1753-2000-8-16]

\section{References}

Bartolommei, N., et al., 2012. Catatonia: A critical review and therapeutic recommendations. Journal of Psychopathology, 18(3), pp. 234-46.

Bouza, C., Lápez Cuadrado, T. \& Amate, J. M., 2010. ‘Physical disease in schizophrenia: A population-based analysis in Spain', BMC Public Health. BioMed Central, 10(1), p. 745. [DOI:10.1186/1471-2458-10-745]

Daniels, J., 2009. Catatonia: Clinical aspects and correlates'. Journal of Neuropsychiatry, 21(4), pp. 371-80. [DOI:10.1176/ jnp.2009.21.4.371] [PMID]

England, M. L., et al., 2011. Catatonia in psychotic patients: Clinical features and treatment response. Journal of Neuropsychiatry, 23(2), pp. 223-26. [DOI:10.1176/appi.neuropsych.23.2.223]

Fink, M., \& Taylor, M. A., 2009. The catatonia syndrome. Archives of General Psychiatry, 66(11), pp. 1173-7. [DOI:10.1001/ archgenpsychiatry.2009.141]

Guggenheim, F. G. \& Babigian, H. M., 1974. Catatonic schizophrenia: Epidemiology and clinical course: A 7-year register study of 798 cases. Journal of Nervous and Mental Disease, 158(4), pp. 291-305. [DOI:10.1097/00005053-197404000-00007]

Kavak, F., 2018. Determination of adherence to treatment of schizophrenia patients in Turkey. Annals of Clinical and Laboratory Research, 6(2), pp. 7-11. [DOI:10.21767/2386-5180.100234]

Leslie, D. L. \& Rosenheck, R. A., 2004. Adherence of schizophrenia pharmacotherapy to published treatment recommendations: Patient, facility, and provider predictors. Schizophrenia Bulletin, 30(3), pp. 649-58. [DOI:10.1093/oxfordjournals.schh bul.a007112]

Martényi, F. et al., 2001. An efficacy analysis of olanzapine treatment data in schizophrenia patients with catatonic signs and symptoms. Journal of Clinical Psychiatry, 62(Suppl.2), pp. 25-7. [PMID]

Northoff, G., et al., 1999. Catatonia as a psychomotor syndrome: A rating scale and extrapyramidal motor symptoms. Movement Disorders, 14(3), pp. 404-16. [DOI:10.1002/15318257(199905)14:33.0.CO;2-5]

Quigley, J., Lommel, K. M. \& Coffey, B., 2009. Catatonia in an adolescent with asperger's disorder. Journal of Child and Adolescent Psychopharmacology, 19(1), pp. 93-6. [DOI:10.1089/ cap.2009.1913] 